\title{
Regulação da Licença de Parentalidade em Pais de Crianças Muito Pré-termo
}

\author{
Regulation of Parental Leave Among Parents of Very Preterm Infants
}

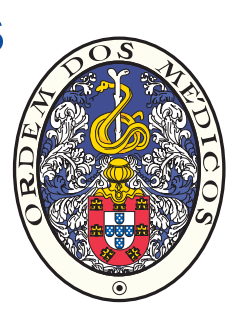

\author{
Mariana AMORIM $\triangle^{1,2}$, Elisabete ALVES ${ }^{1,2}$, Henrique BARROS ${ }^{1,2}$, Susana SILVA ${ }^{1,2}$ \\ Acta Med Port 2015 May-Jun;28(3):281-282
}

Palavras-chave: Licença de Parentalidade; Prematuro.

Keywords: Infant, Premature; Parental Leave.

O nascimento muito pré-termo de uma criança, antes das 32 semanas de gestação, e a sua hospitalização numa Unidade de Cuidados Intensivos Neonatais (UCIN) constitui um acontecimento adverso com repercussões na saúde, bem-estar e qualidade de vida dos pais. ${ }^{1}$ Alterações no desempenho de papéis parentais habituais num ambiente sociotécnico como a UCIN, bem como incertezas quanto à saúde e prognóstico da criança, coloca mães e pais em risco para o desenvolvimento de stress parental, ${ }^{2}$ depressão e ansiedade, ${ }^{3}$ com implicações na sua relação conjugal e qualidade de vida. ${ }^{1}$ Para além disso, o impacto deste acontecimento de vida adverso no bem-estar e estilos de vida $^{4}$ dos pais pode contribuir para aumentar o risco de desenvolvimento de doenças crónicas no futuro, tais como as doenças cardiovasculares. ${ }^{5}$

$\mathrm{O}$ apelo à parentalidade intensiva, centrada na criança, emocionalmente envolvente e orientada por especialistas, traduz-se na expectativa de que os pais permaneçam na UCIN sempre que lhes é possível, estabeleçam contacto físico com o seu bebé, ${ }^{6}$ e participem ativamente nos processos de tomada de decisão quanto aos tratamentos e cuidados a prestar à criança. ${ }^{7}$ A literatura tem mostrado como o envolvimento dos pais na UCIN promove o desenvolvimento e reduz a morbilidade de bebés com baixo peso, contribuindo, simultaneamente, para o bem-estar e diminuição de stress parental, através da promoção de sentimentos de confiança e competência nos pais. ${ }^{7}$

A presença e participação dos pais de crianças internadas em UCIN são facilitadas em contextos sociopolíticos e legais que apoiam e protegem a família, garantindo uma extensão da licença de parentalidade equivalente ao período de hospitalização. Atendendo a que a atual legislação portuguesa prevê apenas um subsídio para assistência a filho durante o período de hospitalização do mesmo com remuneração de $65 \%$ do ordenado de referência, o Partido Comunista Português (PCP) propôs recentemente o Projeto-Lei $n .{ }^{\circ} 621 / \mathrm{XII} / 3{ }^{a}{ }^{a}$ que incluía, entre outras medidas, a criação de uma licença de maternidade específica para os casos de prematuridade, garantindo um subsídio a $100 \%$ durante o período de internamento hospitalar do bebé. Esta proposta foi debatida na Assembleia da República em junho de 2014 e rejeitada com os votos contra do PSD e CDS-PP, abstenção do PS e votos favoráveis do PCP, BE e PEV. ${ }^{8,9}$

No debate parlamentar, as problemáticas que adquiriram relevância foram as políticas de natalidade, os direitos e o superior interesse das crianças e a igualdade de género, destacando-se a pertinência de medidas transversais (e não meramente pontuais) e a necessidade de promover a responsabilidade social das empresas perante as dificuldades financeiras do país. As experiências e necessidades de mães e pais de crianças muito pré-termo estiveram praticamente ausentes do debate, apesar destes serem parceiros fundamentais na conceção de políticas centradas nos cidadãos, conforme preconizado pela União Europeia.

Um estudo desenvolvido por investigadores do Instituto de Saúde Pública da Universidade do Porto, cujo protocolo foi previamente descrito, ${ }^{10}$ visa identificar, entre outros aspetos, a perceção dos pais de crianças muito pré-termo internadas em UCIN quanto a mudanças a efetuar na organização dos cuidados, contribuindo para a inclusão do conhecimento parental na governação da saúde. Entre novembro de 2013 e abril de 2014, foram analisadas 32 entrevistas qualitativas semiestruturadas, realizadas em casal $(n=26)$ e individualmente (seis mulheres), a mães e pais de crianças muito pré-termo internadas numa das sete UCIN nível III do norte de Portugal, quatro meses depois do parto. De seguida, descrevem-se os resultados da análise de conteúdo temática realizada às respostas obtidas às seguintes questões: $\mathrm{Na}$ sua opinião, há alguma coisa mais que os profissionais de saúde podiam fazer por mães e pais de bebés muito prematuros? E o Estado - há alguma coisa mais que possa fazer por mães e pais de bebés muito prematuros?

A reconfiguração da licença de parentalidade foi a proposta identificada mais frequentemente pelas mães e pais, assumindo três direções complementares: 1) garantia de pelo menos um subsídio a $100 \%$ durante o período de

\footnotetext{
1. EPIUnit - Instituto de Saúde Pública. Universidade do Porto. Porto. Portugal.

2. Departamento de Epidemiologia Clínica, Medicina Preditiva e Saúde Pública. Faculdade de Medicina. Universidade do Porto. Porto. Portugal.

$\square$ Autor correspondente: Mariana Amorim. mariana.amorim@ispup.up.pt

Recebido: 18 de Julho de 2014 - Aceite: 15 de Dezembro de 2014 | Copyright $\odot$ Ordem dos Médicos 2015
} 
internamento hospitalar do bebé; 2) criação de condições que facilitem a presença masculina na UCIN, reforçando o suporte social às mães e a participação ativa dos homens na prestação de cuidados à criança; 3) inclusão da prematuridade como um ponderador na fórmula de cálculo do abono de família e na extensão do número de dias do subsídio para assistência a filho durante um ano.

Os entrevistados sugeriram ainda a consagração do direito a um lugar de estacionamento gratuito no parque do hospital durante o internamento da criança, atendendo à despesa acrescida que a deslocação diária entre a residência e a UCIN representa no orçamento familiar. Adicionalmente, defenderam a comparticipação dos leites especiais e das vacinas aconselháveis para prematuros que não estão contempladas no Plano Nacional de Vacinação, assim como o acesso gratuito às vacinas administradas na UCIN para todas as crianças prematuras e não apenas para as que nascem com menos de 28 semanas de gestação. As mães e os pais realçaram ainda a necessidade de estender o período em que a equipa da UCIN pode prestar serviço de urgência aos bebés muito pré-termo depois da alta hospitalar para além de um mês, com o objetivo de evitar o contato com outras crianças doentes na urgência pediátrica geral.

Relativamente às condições físicas da UCIN, a necessidade de investir em cadeirões confortáveis para os pais junto das incubadoras e na criação de um banco público de leite humano também foi mencionada pelos entrevistados, em articulação com o reforço da privacidade na sala de amamentação e a disponibilização de informação sobre a documentação exigida pela Segurança Social.

As narrativas produzidas pelos entrevistados em torno das prioridades políticas e sociais no âmbito da prematuridade em Portugal estão sobretudo associadas às dificuldades por eles sentidas no acesso e na utilização dos serviços de saúde, nomeadamente a acessibilidade em termos económicos e de distância-tempo. Mães e pais reconheceram os custos elevados suportados pelo sistema nacional de saúde no âmbito da prematuridade e enfatizaram a confiança depositada nos profissionais de saúde que cuidam dos seus filhos, argumentos usados para privilegiar medidas que beneficiem todos os pais durante o quotidiano da hospitalização e melhorem as condições da UCIN direcionadas para o cuidado prestado à criança.

A mobilização social e política de mães e pais de crianças muito pré-termo envolve motivações pessoais em relação ao acesso a mais recursos, mas sobretudo preocupações coletivas associadas à promoção da igualdade de género e da equidade no acesso a cuidados de saúde, pilares fundamentais na implementação de políticas de parentalidade centradas na família.

\section{PROTECÇÃO DE PESSOAS E ANIMAIS}

Os autores declaram que os procedimentos seguidos estavam de acordo com os regulamentos estabelecidos pelos responsáveis da Comissão de Investigação Clínica e Ética e de acordo com a Declaração de Helsínquia da Associação Médica Mundial.

\section{CONFIDENCIALIDADE DOS DADOS}

Os autores declaram ter seguido os protocolos do seu centro de trabalho acerca da publicação dos dados de doentes.

\section{CONFLITOS DE INTERESSE}

Os autores declaram não ter quaisquer conflitos de interesse relativamente ao presente artigo.

\section{FONTES DE FINANCIAMENTO}

Este trabalho foi financiado por Fundos FEDER através do Programa Operacional Fatores de Competitividade COMPETE e por Fundos Nacionais através da FCT - Fundação para a Ciência e Tecnologia, no âmbito do projeto FCOMP-01-0124-FEDER-019902 (Ref. ${ }^{a}$ FCT PTDC/CS-ECS/120750/2010), Papéis parentais e conhecimento em unidades de cuidados intensivos neonatais, sediado no Instituto de Saúde Pública da Universidade do Porto (ISPUP), de uma bolsa de doutoramento (PD/BD/105830/2014), de uma bolsa de pós-doutoramento (SFRH/BPD/103562/2014) e da atribuição de um contrato individual no âmbito do programa investigador FCT (IF/00956/2013), cofinanciados pelo Programa Operacional Potencial Humano (POPH).

\section{REFERÊNCIAS}

1. Van Lunenburg A, van der Pal SM, van Dommelen P, van der Pal-de Bruin KM, Bennebroek Gravenhorst J, Verrips GH. Changes in quality of life into adulthood after very preterm birth and/or very low birth weight in the Netherlands. Health Qual Life Outcomes. 2013;11:51.

2. Garel $M$, Bahuaud $M$, Blondel $B$. Conséquences pour la famille d'une naissance très prématurée deux mois après le retour à la maison. Résultats de l'enquête qualitative d'EPIPAGE. Arch Pediatr. 2004;11:1299-307

3. Davis L, Edwards $\mathrm{H}$, Mohay $\mathrm{H}$, Wollin J. The impact of very premature birth on the psychological health of mothers. Early Hum Dev. 2003;73:61-70.

4. Alves E, Azevedo A, Correia S, Barros H. Long-term maintenance of smoking cessation in pregnancy: an analysis of the birth cohort generation XXI. Nicotine Tob Res. 2013;15:1598-607.

5. Yusuf S, Hawken S, Ounpuu S, Dans T, Avezum A, Lanas F, et al. Effect of potentially modifiable risk factors associated with myocardial infarction in 52 countries (the INTERHEART study): case-control study. Lancet. 2004;364:937-52.

6. Arockiasamy V, Holsti L, Albersheim S. Fathers' experiences in the neonatal intensive care unit: a search for control. Pediatrics. 2008;121:e215-22.

7. Gooding JS, Cooper LG, Blaine AI, Franck LS, Howse JL, Berns SD. Family support and family-centered care in the neonatal intensive care unit: origins, advances, impact. Semin Perinatol. 2011;35:20-8.

8. Assembleia da República.pt [homepage na Internet]. Reunião Plenária de 18 de junho de 2014. Diário da Assembleia da República, I série, $1^{\text {a }}$ sessão legislativa, $n^{\circ}$ 95; [consultado 2014 Jul 15]. Disponível em: http://www.parlamento.pt/DAR/Paginas/DAR1Serie.aspx.

9. Assembleia da República.pt [homepage na Internet]. Reunião Plenária de 20 de junho de 2014. Diário da Assembleia da República, I série, $1^{\text {a }}$ sessão legislativa, n97; [consultado 2014 Jul 15]. Disponível em: http://www.parlamento.pt/DAR/Paginas/DAR1Serie.aspx.

10. Alves E, Amorim M, Fraga S, Barros H, Silva S. Parenting roles and knowledge in neonatal intensive care units: protocol of a mixed methods study. BMJ Open. 2014;4:e005941. 
Mariana AMORIM, Elisabete ALVES, Henrique BARROS, Susana SILVA

\section{Regulação da Licença de Parentalidade em Pais de Crianças Muito Pré-termo}

Acta Med Port 2015:28:281-282

Publicado pela Acta Médica Portuguesa, a Revista Científica da Ordem dos Médicos

Av. Almirante Gago Coutinho, 151

1749-084 Lisboa, Portugal.

Tel: +351218428 215

E-mail: submissao@actamedicaportuguesa.com

www.actamedicaportuguesa.com

ISSN:0870-399X | e-ISSN: 1646-0758

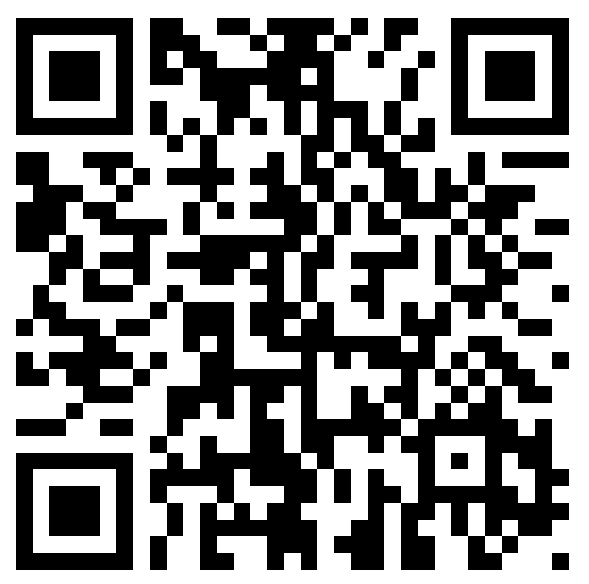

